07

\title{
Изменение строения поверхностей базальта и гранита при трении
}

\author{
(C) В.И. Веттегрень ${ }^{1}$, К. Arora $^{2}$, А.В. Пономарев ${ }^{3}$, Р.И. Мамалимов ${ }^{1}$, И.П. Щербаков ${ }^{1}$, В.Б. Кулик ${ }^{1}$ \\ ${ }^{1}$ Физико-технический институт им. А.Ф. Иофрфе РАН, \\ Санкт-Петербург, Россия \\ ${ }^{2}$ CSIR National Geophysical Research Institute, \\ Hyderabad, India \\ ${ }^{3}$ Институт фоизики Земли им. О.Ю. Шмидта РАН, \\ Москва, Россия \\ E-mail: Victor.Vettegren@mail.ioffe.ru \\ (Поступило в Редакцию 11 декабря 2017 г.)
}

Методами инфракрасной, рамановской, фотолюминесцентной спектроскопии исследовано изменение строения поверхностного слоя при трении образцов базальта и гранита, добытых из скважины в зоне триггерной сейсмичности в районе Койна-Варна, Индия. Установлено, что трение приводит к частичному разрушению кристаллов кварца, альбита, клинопиоксенов и титанита. Вместо них на поверхности образуется тонкий слой минерала с низким коэффициентом трения - каолинита.

Работа выполнена при частичной финансовой поддержке Российского фонда фундаментальных исследований (грант № 16-05-00137) и Российско-индийского проекта РНФ-DST (гранты Российского научного фонда № 16-47-02003 и Департамента науки и технологии правительства Индии - INT/RUS/RSF/P-13).

DOI: 10.21883/FTT.2018.05.45796.343

\section{1. Введение}

Известно [1,2], что в основе механизма землетрясений лежит неустойчивость перемещения блоков горных пород. Это явление объясняется образованием на контакте трущихся поверхностей промежуточного слоя с низким сопротивлением сдвигу. Экспериментальные исследования строения поверхностей горных пород после трения, были начаты в работах [3-11]. Используя методы инфракрасной (IR), рамановской и фотолюминесцентной спектроскопии, авторы установили, что на поверхностях горных пород после трения действительно образуются новые минералы, имеющие низкий коэффициент трения. Было предположено, что их формирование вызвано разрушением кристаллических решеток минералов, входящих в состав горных пород, и образованием химически активных свободных радикалов, которые вызывают химические реакции, приводящие к образованию новых минералов. Такие радикалы, действительно были обнаружены при трении методами фото- и триболюминесценции на поверхностях рифейского и кварцевого песчаников, а также диорита [11-14].

Настоящая работа продолжает цикл этих исследований. Ее цель - исследование изменения строения поверхностей базальта и гранита при трении.

\section{2. Объекты и методы исследования}

Образцы были изготовлены из горных пород, добытых из скважины в зоне триггерной сейсмичности в районе
Койна-Варна, Индия. Первая из них, базальт, извлечена с глубины $314 \mathrm{~m}$, а вторая - гранит - с глубины $689 \mathrm{~m}$.

Базальт содержал $\sim 40 \%$ кристаллов альбита в виде призм, $\sim 40 \%$ агрегатов из кристаллов пироксена и $\sim 15-20 \%$ кристаллов рудного минерала (рис. 1).

Гранит содержал $\sim 40 \%$ кристаллов плагиоклаза неопределенной формы, 25\% кварца, и $\sim 35 \%$ других минералов (рис. 2).

Для трения образцов была использована установка, описанная в [7]. Она состоит из вращающегося диска,

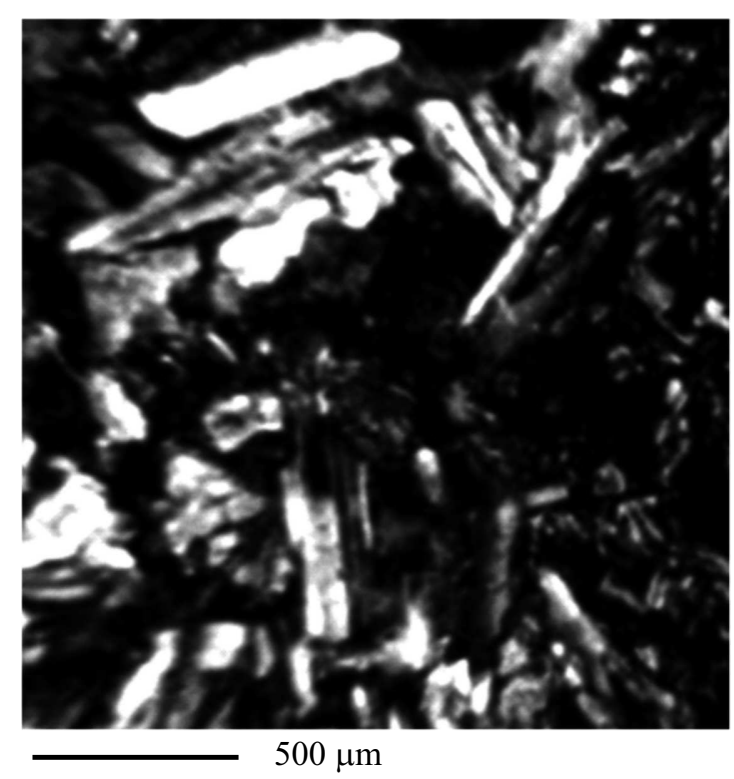

Pис. 1. Фотография шлифа поверхности базальта. 


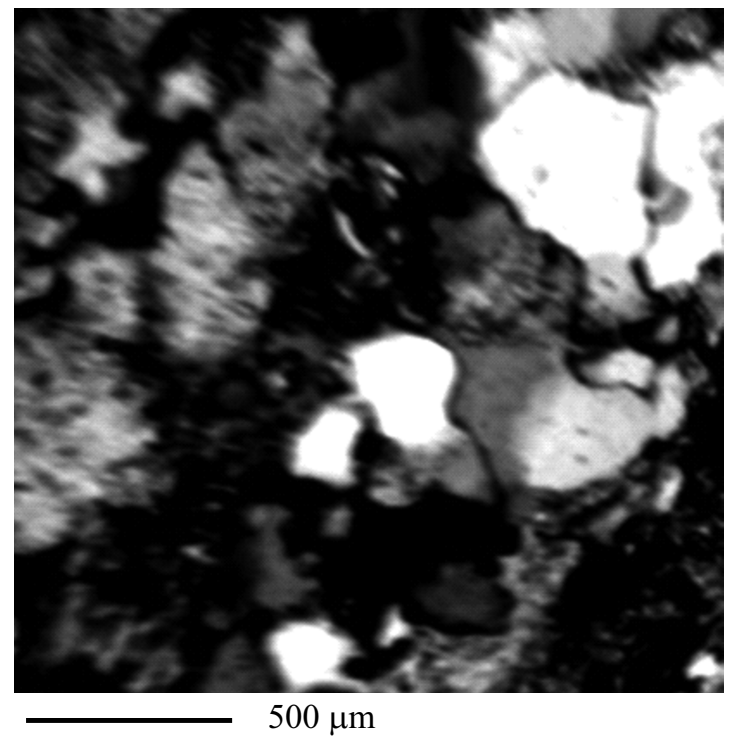

Pис. 2. Фотография шлифа поверхности гранита.

надетого на ось электромотора, и стержня. Диски готовили следующим образом. Из кернов базальта или гранита вырезали кольца шириной $\sim 15 \mathrm{~mm}$ и толщиной $\sim 6 \mathrm{~mm}$. Внутренняя полость колец была заполнена кварцевым песком, скрепленным эпоксидной смолой. В центре дисков сделано отверстие для посадки на ось электромотора. Диаметр диска из базальта - $63 \mathrm{~mm}$, а из гранита $-47 \mathrm{~mm}$. Линейная скорость вращения первого диска составляла $\sim 9.4 \mathrm{~m} / \mathrm{s}$, а второго $-\sim 7 \mathrm{~m} / \mathrm{s}$. Стержни из базальта и гранита имели длину $45 \mathrm{~mm}$ и диаметр - $9.5 \mathrm{~mm}$. Концы стержней затачивались на точильном круге. Диаметр заточенного конца составлял $\sim 2 \mathrm{~mm}$. Это позволяло увеличить величину давления стержня о диск более, чем на порядок.

Чтобы получить спектры фотолюминесценции, была использована лабораторная установка, описанная в [8]. В ней луч светодиода UVTOP280TO39HS (длина волны излучения - $285 \mathrm{~nm}$ ) падал на поверхность образца. Линейные размеры пятна света светодиода на поверхности образца составляли $\sim 3 \mathrm{~mm}$. Возникающее излучение кварцевым световодом направлялось в спектрометр AvaSpec-ULSi2048L-USB2 OEM. Измерения проводились в пяти разных местах, а полученные данные усреднялись.

На величину интенсивности полос в спектре фотолюминесценции сильно влияет рассеяние на шероховатой поверхности образца. Чтобы уменьшить искажения, вызванные рассеянием, мощность излучения лазера подбиралась такой, чтобы величина интенсивности света, отраженного от поверхности, была одинаковой.

Для записи ИК-спектров отражения использовали Фурье-спектрометр IR-21 „Prestige“. Диаметр пятна луча ИК-излучения на исследуемой поверхности $-\sim 4 \mathrm{~mm}$. Полученные спектры пересчитывались в спектры затухания (мнимой части диэлектрической постоянной $\left.\varepsilon^{\prime \prime}(v)\right)$.
С этой целью использовался модифицированный метод Крамерса-Кронига [15].

Рамановские спектры в геометрии обратного рассеяния света были получены в УНУ „Физика, химия, и механика кристаллов и тонких пленок“ (ИПМаш РАН, Санкт-Петербург) на конфокальной рамановской установке Witec Alpha 300R. Длина волны возбуждающего лазера - $532 \mathrm{~nm}$. Размер пятна света лазера на поверхности образца равнялся $\sim 5 \mu \mathrm{m}$. Проводилось от 5 до 10 измерений в разных местах на поверхности, полученные данные усреднялись.

Амплитуда электрического вектора света, падающего на поверхность поглощающего образца, затухает экспоненциально от поверхности в глубь. Эффективная толщина поверхностного слоя, о строении которого несут информацию спектры, задана глубиной $h$, на которой амплитуда электрического вектора света уменьшается в $e \sim 2.7$ раз (e - основание натуральных логарифмов), а интенсивность света - в $e^{2} \sim 8$ раз. Она вычислялась по формуле [16]

$$
h \approx \frac{1}{4 \pi \nu k},
$$

где $k$ - показатель поглощения, $v$ - частота света.

Как уже упоминалось выше, поверхность образца сильно рассеивает свет. По этой причине, когда использовались методы рамановской и фотолюминесцентной спектроскопии, оказалось невозможным точно определить эффективную толщину поверхностного слоя. Грубая оценка, по величине рассеянного излучения на длине волны источника (лазера для случая рамановских спектров или светодиода - для спектров фотолюминесценции), показала, что величина $h$ составляет $\sim 2 \mu \mathrm{m}$.

Влияние рассеяния, когда применяли метод ИК-спектроскопии значительно меньше, и эффективную толщину оценивали, используя формулу (1) (полученное значение $h$ приведено ниже - на рис. 8$)$.

\section{3. Результаты измерений и их обсуждение}

Рамановские спектры поверхности базальта и гранита до и после трения показаны на рис. 3 и 4. Полосы 187 , $203,263,285,300,841,760,1050,1090$ и $1113 \mathrm{~cm}^{-1}$ в спектре базальта соответствуют колебаниям кристаллов альбита [17], а 657 и $674 \mathrm{~cm}^{-1}$ - пироксена [18]. Частоты максимумов полос 285, 508, 562 и $990 \mathrm{~cm}^{-1}$, соответствующих колебаниям кристаллических решеток этих минералов, отличаются мало и в спектре соответствующие им полосы наложены друг на друга.

Полосы 127, 207, 355 и $465 \mathrm{~cm}^{-1}$ в спектре гранита соответствуют колебаниям кристаллической решетки кварца [19]. Остальные полосы $(164,251,264,288,355$, 477 и $\left.507 \mathrm{~cm}^{-1}\right)$ приписаны колебаниям кристаллической решетки альбита [17].

Прежде, чем сделать выводы из полученных данных, напомним, что измеренная интенсивность полос в ра- 
мановских спектрах сильно зависит от степени шероховатости поверхности, которая изменяется при трении. Поэтому вышеприведенные спектры несут информацию не об абсолютной концентрации минералов, а только о соотношении их концентраций.
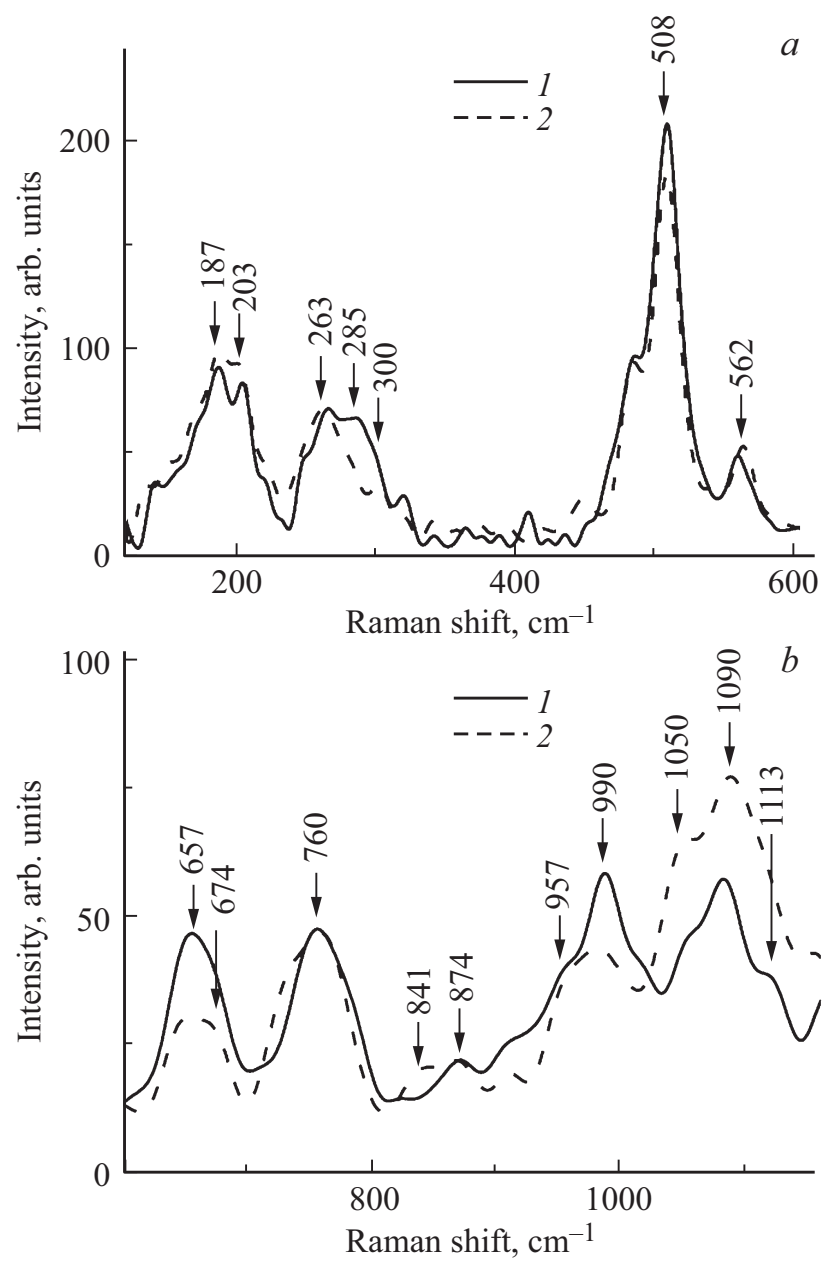

Рис. 3. Рамановские спектры базальта до (1) и после трения (2).

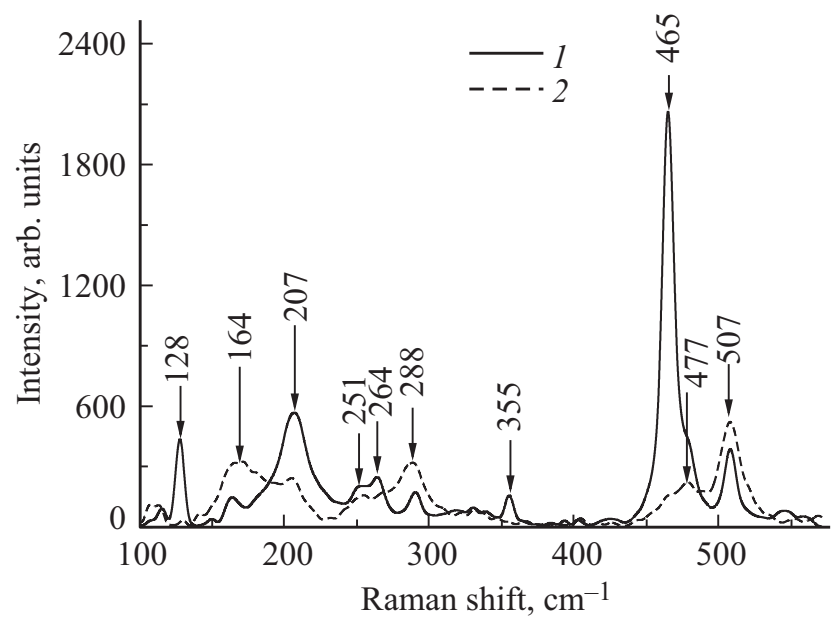

Рис. 4. Рамановские спектры поверхности гранита до (1) и после (2) трения.

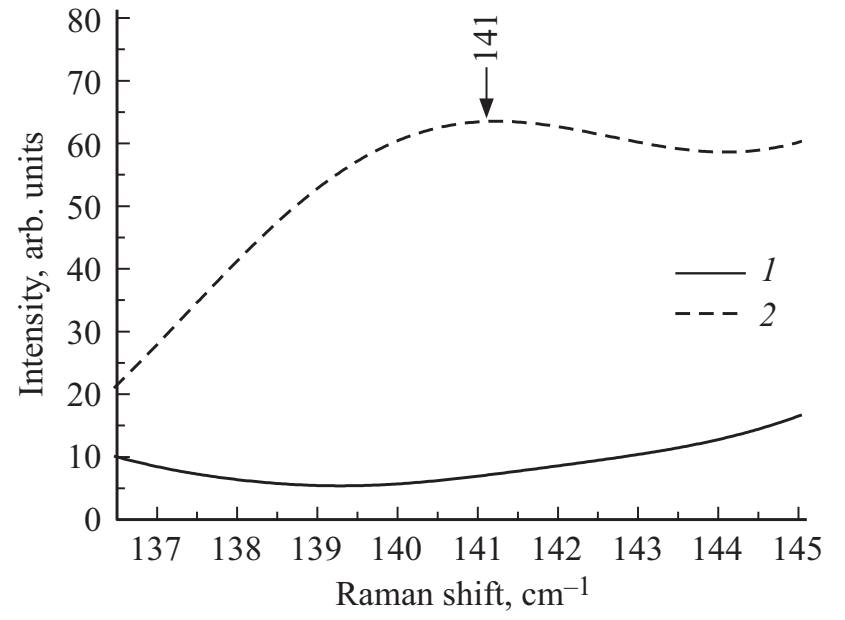

Рис. 5. Рамановский спектр гранита в диапазоне $136-145 \mathrm{~cm}^{-1}$ до (1) и после (2) трения.

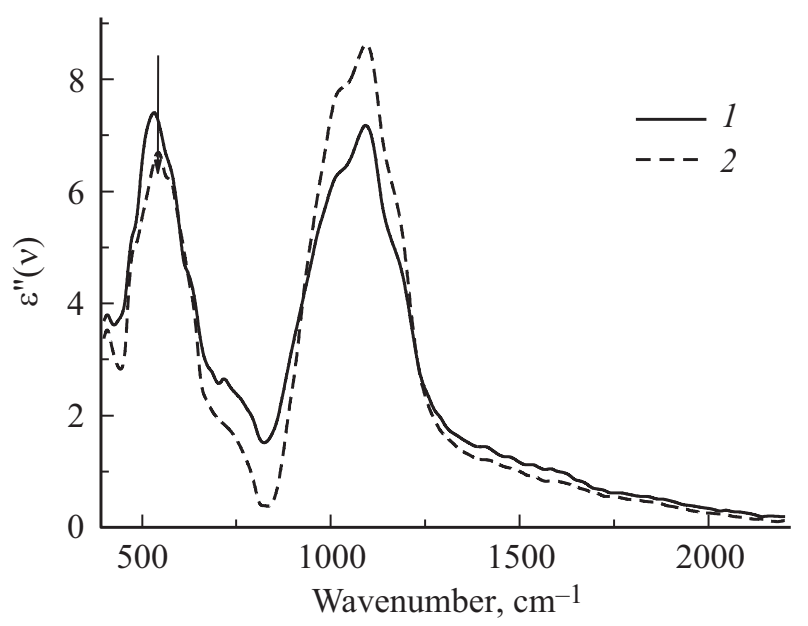

Рис. 6. Спектр затухания инфракрасного излучения в поверхностном слое базальта до (1) и после (2) трения.

В спектрах базальта после трения интенсивность полос 657 и $674 \mathrm{~cm}^{-1}$ уменьшилась, а 841,957 и $1090 \mathrm{~cm}^{-1}$ увеличилась. Это показывает, что в поверхностном слое толщиной $\sim 2 \mu \mathrm{m}$ кристаллы пироксена частично разрушились. В результате относительное содержание кристаллов альбита в этом слое увеличилось.

После трения гранита интенсивность полос, соответствующих колебаниям кристаллической решетки кварца, резко уменьшилась, а альбита - выросла. Одновременно в области $135-145 \mathrm{~cm}^{-1}$ появляется слабая полоса $141 \mathrm{~cm}^{-1}$ (рис. 5), соответствующая колебаниям кристаллической решетки каолинита [20]. Эти результаты показывают, что после трения в поверхностном слое гранита толщиной $\sim 2 \mu \mathrm{m}$ содержание кристаллов кварца уменьшилось, а альбита увеличилось. Одновременно в этом слое образовался каолинит.

На рис. 6 приведены спектры затухания $\varepsilon^{\prime \prime}(v)$ инфракрасного излучения в поверхностном слое базальта, а на рис. 7 - гранита до и после трения. 


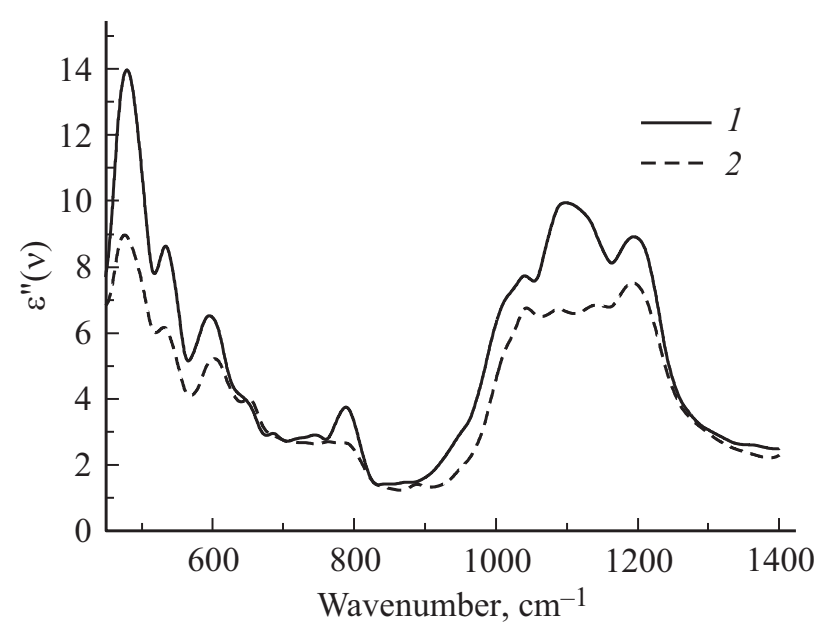

Рис. 7. Спектр затухания инфракрасного излучения в поверхностном слое гранита до (1) и после (2) трения.

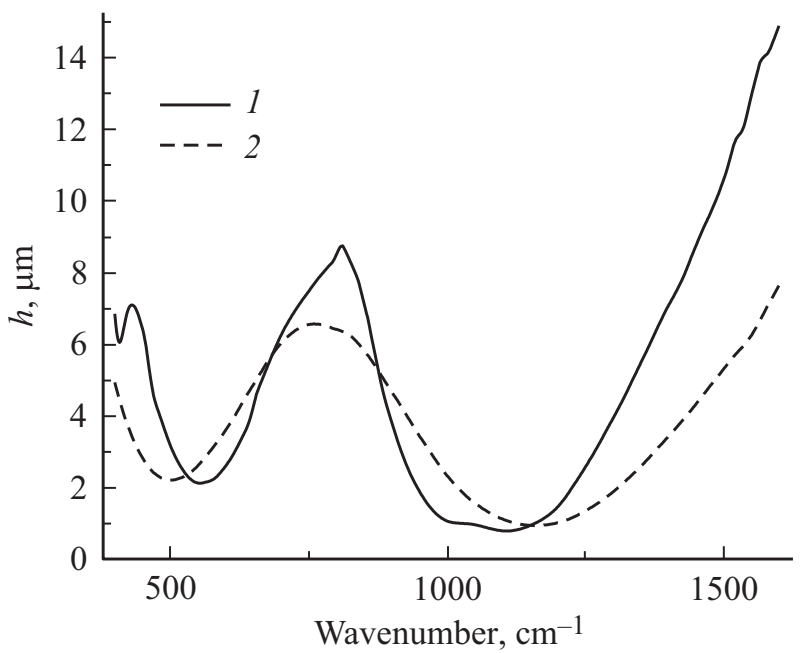

Pис. 8. Зависимость эффективной толщины $h$ поверхностного слоя от частоты инфракрасного излучения для базальта $(1)$ и гранита (2).

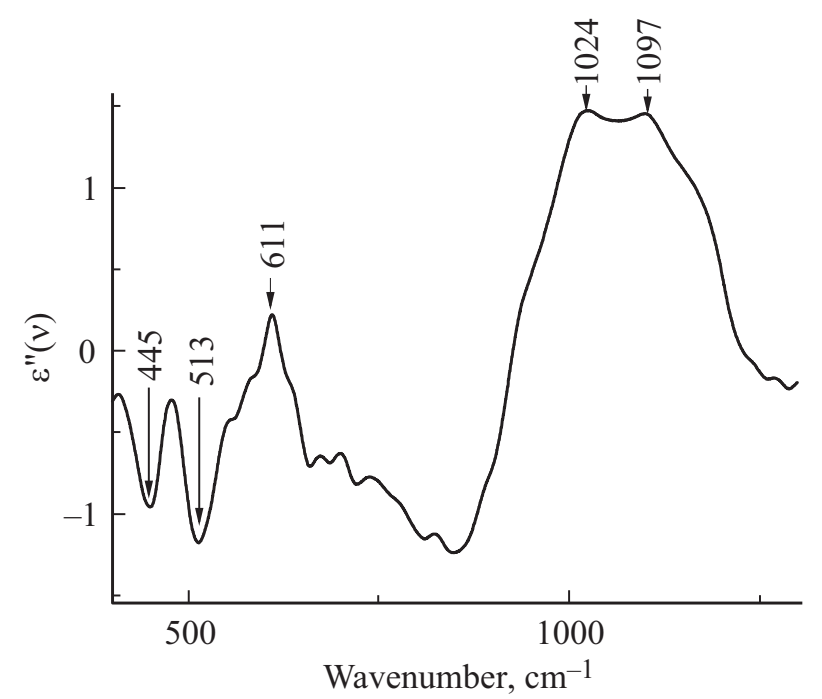

Рис. 9. Разность спектров затухания инфракрасного излучения в поверхностном слое базальта.
Отметим, что, в отличие от рамановской спектроскопии (в которой эффективная толщина постоянна и задана только частотой источника излучения), в ИК-спектроскопии эффективная толщина зависит от показателя поглощения и значительно изменяется при изменении частоты излучения (см. рис. 8).

Рассмотрим сначала, как изменяются спектры $\varepsilon(v)$ при трении базальта (рис. 6). Они образованы за счет наложения друг на друга полос, соответствующих колебаниям кристаллов плагиоклазов [21,22], пироксенов [23] и каолинита [24-26]. Видно, что интенсивность спектра после трения в области $390-910 \mathrm{~cm}^{-1}$ уменьшается, а в области $910-1200 \mathrm{~cm}^{-1}$ - растет. Более ярко эти изменения проявляются в разностном спектре, полученном путем вычитания спектра после трения из спектра до него (рис. 9). Видно, что трение вызвало увеличение интенсивности полос 610, 1024 и $1097 \mathrm{~cm}^{-1}$, соответствующих колебаниям кристаллической решетки каолинита [24-26]. Одновременно уменьшилась интенсивность полос - 445 и $513 \mathrm{~cm}^{-1}$, соответствующих колебаниям кристаллической решетки пироксенов, и полос в области 630-920 $\mathrm{cm}^{-1}$, соответствующих колебаниям кристаллической решетки альбита [21,22].

Это показывает, что в поверхностном слое базальта толщиной $\sim 4 \mu \mathrm{m}$ (рис. 8 ) трение вызывает разрушение не только пироксенов, но и альбитов. Одновременно в слое толщиной $\sim 1 \mu \mathrm{m}$ сформировался каолинит.

На рис. 7 показаны спектры гранита до и после трения. Они образованы при наложении друг на друга полос, соответствующих колебаниям кристаллических решеток кварца [27-29], альбита и каолинита. Видно, что после трения величина $\varepsilon^{\prime \prime}(v)$ во всем спектре уменьшается. Это показывает, что концентрация кварца, титанита и альбита в поверхностном слое толщиной от 1 до $6 \mu \mathrm{m}$ после трения уменьшается. В отличие от спектров базальта, образование каолинита (зафиксиро-

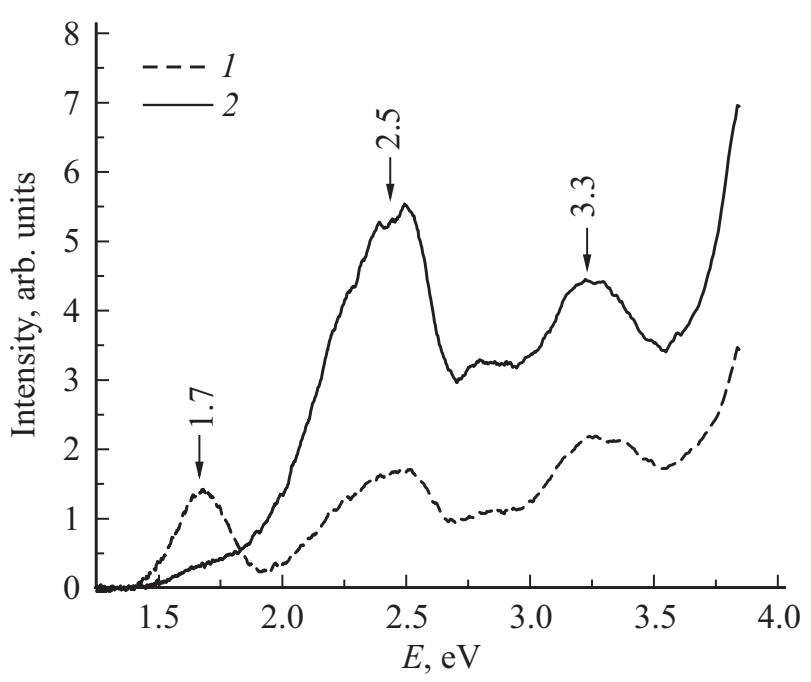

Рис. 10. Спектры фотолюминесценции гранита до (1) и после (2) трения. 
ванное методом рамановской спектроскопии) не привело к росту интенсивности в области $1000-1100 \mathrm{~cm}^{-1}$. Это, вероятно, связано с тем, что в этой же области частот расположены полосы, соответствующие колебаниям кварца, интенсивность которых после трения резко уменьшилась. Это уменьшение и подавило рост интенсивности, вызванный образованием каолинита.

Анализ спектров фотолюминесценции позволяет получить сведения о дефектах атомного размера в кристаллах горных пород. Интенсивность спектров базальта оказалась слишком слабой, и получить их не удалось. Спектры гранита до и после трения показаны на рис. 10. Максимумы $1.7,2.5$ и $3.3 \mathrm{eV}$ в этих спектрах соответствуют ионам - $\mathrm{Fe}^{3+}$, радикалам $-\mathrm{O}-\mathrm{Si}^{2+}$ и электронным ловушкам в плагиоклазе [30-32]. Рассмотрение рис. 10 показывает, что после трения гранита концентрация ионов $\mathrm{Fe}^{3+}$ уменьшается в $\sim 8$ раз, а радикалов - $\mathrm{O}-\mathrm{Si}^{2+}$ и электронных ловушек в плагиоклазе, наоборот, увеличивается в 3-4 раза.

\section{4. Заключение}

После трения базальта на его поверхности уменьшается концентрация пироксена и альбита. Трение образцов гранита друг о друга привело к разрушению кварца, альбита и титанита. Одновременно, в поверхностных слоях базальта и гранита, толщиной $\sim 1 \mu \mathrm{m}$ образуется каолинит.

\section{Список литературы}

[1] J.D. Byerlee. Pure Appl. Geophys. 116, 615 (1978).

[2] J.H. Dieterich. J. Geophys. Res. B 83, 3940 (1978).

[3] Г.А. Соболев, С.М. Киреенкова, Ю.А. Морозов, А.И. Смульская, В.И. Веттегрень, В.Б. Кулик, Р.И. Мамалимов. Физика Земли 9-10, 17 (2012).

[4] Г.А. Соболев, В.И. Веттегрень, В.В. Ружич, Л.А. Иванова, Р.И. Мамалимов, И.П. Щербаков. Вулканология и сейсмология 3, 3 (2015).

[5] Г.А. Соболев, В.И. Веттегрень, В.В. Ружич, С.М. Киреенкова, А.И. Смульская, Р.И. Мамалимов, В.Б. Кулик. Геофиз. исследования 1, 4, 5 (2015).

[6] Г.А. Соболев, В.И. Веттегрень, С.М. Киреенкова, В.Б. Кулик, Р.И. Мамалимов, Ю.А. Морозов, А.И. Смульская, И.П. Щербаков. Нанокристаллы в горных породах. ГЕОС, М. (2016). $102 \mathrm{c}$.

[7] В.И. Веттегрень, А.В. Пономарев, И.П. Щербаков, Р.И. Мамалимов. ФТТ 59, 569 (2017).

[8] В.И. Веттегрень, Р.И. Мамалимов, В.Б. Кулик, А.В. Патонин, А.В. Пономарев, Г.А. Соболев, И.П. Щербаков. ФТТ 59, 1315 (2017).

[9] В.И. Веттегрень, А.В. Пономарев, К. Арора, И.П. Щербаков, Р.И. Мамалимов. ФТТ 59, 1319 (2017).

[10] В.И. Веттегрень, А.В. Пономарев, Г.А. Соболев, В.Б. Кулик, Р.И. Мамалимов, И.П. Щербаков, А.Я. Башкарев. ФТТ 60, 17 (2018).

[11] В.И. Веттегрень, В.С. Куксенко, И.П. Щербаков. Физика Земли 5, 134 (2016).
[12] В.И. Веттегрень, Г.А. Соболев, А.В. Пономарев, И.П. Щербаков, Р.И. Мамалимов. ФТТ 59, 931 (2017).

[13] В.И. Веттегрень, А.В. Пономарев, И.П. Щербаков, Р.И. Мамалимов. ФТТ 59, 1557 (2017).

[14] В.И. Веттегрень, А.В. Пономарев, И.П. Щербаков, Р.И. Мамалимов. ФТТ 59, 2263 (2017).

[15] A.B. Kuzmenko. Rev. Sci. Instr. 76, 083108 (2005).

[16] M. Born, E. Wolf. Principles of optics. 2-ed. Pergamon press, Oxford. (1964). $856 \mathrm{p}$.

[17] J.J. Freeman, A. Wang, K.E. Kuebler, B.L. Jolliff, L.A. Haskin. Canad. Mineral. 46, 1477 (2008).

[18] E. Huang, C.H. Chen, T. Huang, E.H. Lin, Ji-An Xu. Am. Mineral. 85, 473 (2000).

[19] K. De Boer, A.P.J. Jansen, R.A. van Santen, G.W. Parker. Phys. Rev. B 54, 2, 826 (1996).

[20] L.R. Frost. Glays Glay Miner. 43, 191 (1995).

[21] F. Laves, S. Hafner. Z. Kristallogr. 108, 52 (1956).

[22] D.B. Stewart, T.L. Wright. Bull. Soc. Mineral. Cristallogr. 97, 356 (1974).

[23] P. Makreski, G. Jovanovski, A. Gajović, T. Biljan, D. AngelovskiA, R. Radojko Jaćimović. J. Molecular Struct. 788, 1-3, 102 (2006).

[24] N.V. Chukanov. Infrared spectra of mineral species. Springer Science + Business Media, Dordrecht. (2014). 1726 p.

[25] B.J. Saikia, P. Gopalakrishnarao. J. Mod. Phys. 1, 206 (2010).

[26] K.A.H. Saeeda, K.A. Kassima, N.Z.M. Yunusa, H. Nurb. J. Teknolog. 72, 3, 83 (2015).

[27] W.G. Spitzer, D.A. Kleinman. Phys. Rev. 121, 1324 (1961).

[28] J. Etchepare, M. Merian, P.J. Kaplan. Chem. Phys. 60, 1873 (1974).

[29] K. Iishi, H. Yamacuchi. Am. Mineral. 60, 907 (1975).

[30] J. Götze. Microsc. Microanal. 18, 1270 (2012).

[31] D.J. Huntley, D.I. Godfrey-Smith, M.L.W. Thewalt. Nature. 313, 105 (1985).

[32] D.J. Huntley, D.I. Godfrey-Smith, E.H. Haskell. Nuclear Tracks and Rad. Meas. 18, 127 (1991). 